\title{
Self-Monitored Motives for Smoking Among College Students
}

\author{
Thomas M. Piasecki, Alison E. Richardson, and Shawn M. Smith \\ University of Missouri-Columbia
}

\begin{abstract}
College student smokers $(N=50)$ were asked to carry electronic diaries for 14 days and record smoking events $(n=1,139)$. They indicated why they were smoking each cigarette on a checklist of potential motives. Results suggest that a desire to reduce craving (62.8\% of occasions) and habit/automatic processes $(42.8 \%)$ were the most frequent motives. More dependent and daily smokers were especially likely to endorse smoking to reduce craving and for habit/automatic reasons and were less likely to cite coping with negative emotion as a reason for smoking. Dependent and daily smokers were more likely to endorse at least 1 dependence-like motive and were less likely to exclusively attribute smoking to nondependence motives. Self-monitored motives appeared valid, according with conceptually related states, activities, and events in the diary records. Diary-recorded motives were compared with smokers' responses to a retrospective motives questionnaire administered at baseline. The 2 assessment modes produced discrepant estimates of the most influential motivational processes. Questionnaire responses incompletely forecast conceptually similar diary-reported motives. Dependence and daily smoking showed a different pattern of associations with diary-based versus retrospective motives measures.
\end{abstract}

Keywords: college students, smoking motives, self-monitoring, tobacco dependence, stimulus control

Smoking behavior is common on college campuses. Approximately $37 \%$ of full-time college students report using cigarettes in the past year, and $24 \%$ report smoking in the past 30 days (Johnston, O’Malley, Bachman, \& Schulenberg, 2005). Most students who smoke are light smokers. Among students smoking in the past 30 days, $65-75 \%$ smoke fewer than 10 cigarettes per day, and 30-45\% smoke less than daily (Rigotti, Lee, \& Wechsler, 2000; Wechsler, Rigotti, Gledhill-Hoyt, \& Lee, 1998). College is a time in which many students begin smoking, quit, or progress toward stable, dependent smoking (Kenford et al., 2005; Wechsler et al., 1998; Wetter et al., 2004). Investigators have grown increasingly interested in why college students smoke.

Psychological accounts of smoking frequently assert that the early portion of the smoking career is characterized by strong stimulus control of cigarette use (e.g., Leventhal \& Cleary, 1980; Mayhew, Flay, \& Mott, 2000; Shiffman \& Paty, 2006). Fledgling smokers are presumed to smoke in circumscribed settings to attain specific psychological benefits of smoking (e.g., social enhancement, anxiety reduction, stimulation). With greater exposure, physiological adaptations to nicotine and associative learning mechanisms are presumed to erode stimulus control, culminating in a dependent state in which smoking becomes routinized and self-reinforcing, with cues signaling nicotine deprivation sufficient to trigger smoking.

Thomas M. Piasecki, Alison E. Richardson, and Shawn M. Smith, Department of Psychological Sciences, University of MissouriColumbia.

This work was supported by National Institute on Drug Abuse Grant DA016330.

Correspondence concerning this article should be addressed to Thomas M. Piasecki, Department of Psychological Sciences, 210 McAlester Hall, University of Missouri-Columbia, Columbia, MO 65211. E-mail: piaseckit@missouri.edu
This perspective suggests that long-term smokers will be relatively uniform with respect to smoking triggers because all will approach an asymptotic dependent state. Populations with less cumulative smoking experience may exhibit greater betweensubjects diversity in reasons for smoking. A variety of evidence suggests smoking among light-smoking college students may be more elective than compulsive. For example, students' smoking varies by day of the week (Colder et al., 2006) and time of day (Krukowski, Solomon, \& Naud, 2005). Many students report smoking exclusively in social situations (Moran, Wechsler, \& Rigotti, 2004), and social smoking is constrained by delicate self-presentational considerations (Nichter et al., 2006). Nonsmoking students cite having friends who smoke and a desire to cope with stress as reasons to try cigarettes (DeBernardo \& Aldinger, 1999).

From the late 1960s through the 1980s, investigators attempted to characterize individual differences in stimulus control of smoking using a variety of smoking-motives questionnaires (Tate, Schmitz, \& Stanton, 1991). These instruments assessed distinct psychological functions of cigarettes (e.g., cognitive enhancement, taste, anxiety relief) and/or antecedents of smoking (e.g., social settings, negative affect). A smoker's profile of scores across motive subscales was presumed to reveal his or her most important triggers. It was hoped these measures would foster insights into the physiological and associative bases of dependence and aid treatment tailoring.

Research into self-reported motives for smoking ultimately foundered. In an incisive review of this line of research, Shiffman (1993) contended popular measures of smoking motives often lacked basic face validity and had failed to demonstrate compelling and consistent evidence of construct validity or clinical utility. Shiffman questioned the value of motives scales for understanding chronic adult smoking, noting that a higher-order "smoking drive" factor could account for the scattered correlations between motives 
questionnaires and criterion variables parsimoniously. In light of the frequency of smoking and the inherent limitations of memory, Shiffman suggested smokers may not be capable of accurately reporting their own motives using retrospective questionnaires. To avert memory bias, computer-assisted self-monitoring was suggested for probing stimulus control theories.

In line with Shiffman's (1993) recommendations, Ecological Momentary Assessment (EMA; Stone \& Shiffman, 1994) designs have been widely adopted in smoking research. EMA designs combine aspects of two field research traditions: the time-based sampling strategy of the Experience Sampling Method (ESM; Csikszentmihalyi \& Larson, 1987) and the event-based strategy used in self-monitoring research (e.g., McFall \& Hammen, 1971). This combination is powerful for studying stimulus control because comparison of variables assessed at smoking-related moments to their time-sampled base rates can detect the unique antecedents of smoking. EMA studies focus on immediate experience, minimizing the need for participant retrospection (Schwartz, Neale, Marco, Shiffman, \& Stone, 1999; Shiffman et al., 1997). EMA studies typically use computerized diary platforms, which increase data quality and may promote better compliance with the diary protocol (cf. Green, Rafaeli, Bolger, Shrout, \& Reis, 2006; Stone, Shiffman, Schwartz, Broderick \& Hufford, 2002).

This transition in research design was accompanied by a more subtle change in assessment emphasis. Following the logic of EMA designs, recent investigations have focused exclusively on the situational and subjective correlates of smoking. Smokers' self-reported reasons for cigarette use have been comparatively neglected, perhaps because these judgments are inherently linked to smoking events and therefore cannot be time-sampled.

Theoretically, the stimulus conditions preceding smoking and the psychological functions of smoking are closely linked but discriminable constructs (Leventhal \& Cleary, 1980; Shiffman, 1993). EMA designs permit inferences about smoking functions by isolating smoking-associated stimulus conditions. Asking smokers to self-monitor their reasons for smoking assesses the (perceived) functions of smoking more directly and thus may represent a valuable, complementary response channel within a broad stimulus control framework. The disappointing track record of retrospective motives questionnaires did not necessitate abandoning assessments of smokers' attributions for smoking. In principle, retrospective bias can be diminished by collecting motive judgments at the time cigarettes are smoked within the self-monitoring arm of an EMA design. Assessments of smoking motives may be especially valuable in younger populations, such as college students, for whom a general, dependence-like "smoking drive" may be insufficient for explaining many smoking events (Colby, Tiffany, Shiffman, \& Niaura, 2000).

To date, only a small number of field studies have assessed smokers' immediately reported motives for smoking (Joffe, Lowe, \& Fisher, 1981; Klitzke, Irwin, Lombardo, \& Christoff, 1990; Leventhal \& Avis, 1976; Tate \& Stanton, 1990). In all of these studies, field data were collected to evaluate the validity of the Reasons for Smoking questionnaire (RFS; Horn \& Waingrow, 1966). Correlations between the field data and congruent RFS subscales were weak and inconsistent. Apart from these findings (which may challenge the validity of the RFS, self-monitored motives, or both), little is known regarding the validity of smokers' real-time attributions for smoking.

In this study, college student smokers carried electronic diaries in their natural environments and were asked to indicate why they were smoking each time they logged a cigarette. The study had two primary aims. First, we sought to characterize the frequency with which particular motives for smoking were cited by college students in the course of daily experience. Based on theoretical accounts of smoking progression and prior research on student smoking, we expected students would frequently cite motives indicative of situation-specific goals for smoking relevant at any stage of the smoking career (e.g., affect modulation, social motives). We expected later-emerging, addiction-like motives (e.g., craving, smoking in anticipation of restrictions, habit) would be associated with tobacco dependence and daily smoking. A secondary goal was to evaluate the construct and discriminative validity of self-monitored motives for smoking. Therefore, we also tested whether diary-reported motives corresponded with relevant, contemporaneously measured circumstances and states and whether the frequency of self-monitored motives could be forecast from a retrospective measure of smoking motives.

\section{Method}

\section{Participants}

Data were drawn from a larger study of 130 students (73 nonsmokers and 57 smokers). Participants were students enrolled in introductory psychology courses at the University of MissouriColumbia. Participants were awarded the maximum number of course credit points for research participation and were also paid $\$ 75$.

Three smokers dropped out of the study before going into the field with the electronic diary and a fourth, a light smoker, did not report any smoking events in the electronic diary. Two participants reported being daily smokers but logged two or fewer smoking events. These participants were excluded from analyses. Data from an older, returning student (age 32, 14-year smoking history) were also excluded. The remaining 50 smokers initiated a total of 1,139 smoking records, and these form the basis of this report. Women made up $62 \%$ of the analyzed sample, and $85 \%$ of the sample were White. The mean age was 18.5 years (range: 18-21). Seventeen participants were nondaily smokers; at baseline, they reported smoking an average of 3.4 days per week (range: 2-6) and an average of 4.4 cigarettes on smoking days (range: $2-15$ ). They had smoked an average of 1.7 years (range: $0-4$ ). The remaining 33 smokers reported smoking daily at baseline, with an average of 6.8 cigarettes per day (range: 3-20); they had smoked an average of 2.0 years (range: $0-6)$. Daily smokers contributed $976(85.7 \%)$ of the study smoking records, consistent with their higher smoking frequency and greater representation in the study census.

\section{Electronic Diary}

Electronic diaries were implemented on personal digital assistants (PDAs; Palm Zire, Palm, Inc., Sunnyvale, CA) equipped with commercially available database software (Pendragon Forms, Pendragon Software, Libertyville, IL). Diary forms were configured so that participants were required to enter an in-range response for all 
numerical variables before moving to successive items. Items for which the response set consisted of a multi-item checklist, however, could be skipped due to software constraints. Participants could not move backward in an interview and could not review or edit completed interviews.

\section{Procedure}

Students volunteered via a Web-based recruitment system and were scheduled for orientation sessions in groups of 5-10. A low threshold was set for inclusion in the smoking group: volunteers had to report smoking at least one cigarette per week over the past month.

At orientation, participants were issued a PDA, trained to use the device, and informed about the study procedure. Briefly, the study used an EMA design with four types of diary interviews: (1) time-based signaled prompts, (2) user-initiated presmoking reports, (3) user-initiated quick smoke interviews, and (4) userinitiated postsmoking interviews. Although time sampling was used, the present analyses are limited to data from the selfmonitoring component of the design. Analyses focused on data collected from the presmoking $(n=1,034,91 \%$ of smoking reports) and quick smoke $(n=105,9 \%)$ records only because these were the interviews in which motives for smoking were assessed. Smokers were instructed to initiate a presmoking interview each time they began to smoke a cigarette. The quick smoke interview, an abbreviated version of the presmoking interview, was intended to reduce assessment burden during periods of chain smoking. Smokers were instructed to complete the quick smoke interview if they had completed a full presmoking interview within the past 30 minutes.

Participants were asked to carry the PDAs in their natural environments for 14 days and began actively recording diary data the day after the orientation session. When in the field, participants made follow-up visits to the laboratory every 3-4 days so that study staff could download the data, field any protocol or technical questions, and encourage compliance. Recording took place during the fall and winter semesters, excluding Thanksgiving, winter, and spring breaks. On average, participants completed 12.7 days of self-recording.

\section{Diary Compliance}

Smokers completed an average of $81.3 \%$ of the expected random prompt interviews (adjusting for the number of days each participated in the study), suggesting reasonable compliance with the overall diary protocol. We computed an expected number of cigarette events for each smoker, taking into account their selfreported smoking rate, smoking days per week, and number of days of successful diary monitoring. By this estimate, a low proportion of expected cigarettes were recorded in the diary by both daily smokers (35\% of expected value) and nondaily smokers $(32 \%)$. Across smokers, there was a significant correlation between the number of expected cigarettes and the number of smoking records provided $(r=.72, p<.001)$. Relative to nondaily smokers, daily smokers reported smoking on a higher proportion of monitoring days, Daily $M=.75, S D=.25$; Nondaily $M=.47$, $S D=.22, t(48)=3.85, p<.01$.

\section{Measures}

Self-monitored motives for smoking. The presmoking and quick smoke interviews included an item reading "Why are you smoking this cigarette?" Response options were (a) Reduce Craving, (b) Soon Going Where Can't Smoke, (c) Cope with Negative Emotion, (d) Enhance Positive Emotion, (e) Habit/Automatic, (f) Opportunity to Socialize, (g) Break from Work/Studying, and (h) Boredom/To Kill Time. For analysis, responses were recoded into separate variables indicating the presence or absence of each motive. Respondents could check more than one motive per smoking event. This item was skipped in $27(2.3 \%)$ interviews. These missing responses were counted in analyses estimating the prevalence of individual motives but were treated as missing values in other analyses.

In supplemental analyses, we examined the prevalence of reporting any nondependence motive (Cope with Negative Emotion, Enhance Positive Emotion, Opportunity to Socialize, Break from Work/ Studying, or Boredom/To Kill Time) and any dependence-like motive (Reduce Craving, Soon Going Where Can't Smoke, or Habit/ Automatic). This scheme distinguishes between situation-specific motives applicable at any stage of smoking involvement and those motives presumed to evolve with greater smoking exposure. We also examined the rates at which cigarettes were attributed only to nondependence motives or only to dependence-like motives.

Tobacco dependence and daily smoking. The Fagerstrom Test for Nicotine Dependence (FTND; Heatherton, Kozlowski, Frecker, \& Fagerstrom, 1991) was administered at the orientation session ( $\alpha=.55$ ). Of the study group, 30 smokers $(60 \%)$ reported an FTND score of 0 . The percentage of smoking occasions at which each motive was endorsed was computed separately for smokers with FTND scores of 0 and for smokers with FTND scores $>0$ to illustrate dependence effects. We also tested whether motives for smoking were related to self-reported daily smoking. Daily smoking was related to, but not completely redundant with, FTND scores; 15 daily smokers obtained a score of 0 on the FTND, and 2 nondaily smokers achieved a non- 0 score.

Contemporaneous validation measures. Data reported in other sections of the same smoking reports were used to gauge the validity of the reported motives for smoking.

To evaluate reports of emotion-related smoking motives, we examined levels of contemporaneously reported negative and positive affect. Negative and positive affect were each assessed with three items adapted from the Positive and Negative Affect Schedule (Watson, Clark, \& Tellegen, 1988) scored on a Likert scale from 1 (not at all) to 5 (extremely). The item stems asked "How have you felt in the past 15 minutes?" Negative affects assessed were "scared," "upset," and "distressed" $(\alpha=.71$ across all smoking reports). Positive affects were "enthusiastic," "interested," and "proud" $(\alpha=.78)$. Current affect was not assessed in the abbreviated quick smoke interviews.

Smokers were asked in the presmoking interviews about recent stressors with an item reading "Did a stressful event occur or begin in the past 15 minutes?" Answers to this question were used to probe the validity of smoking attributed to a desire to cope with negative emotions.

In the presmoking interviews, smokers were asked to indicate whether they had consumed alcohol or marijuana in the past hour; we tested whether smoking to enhance positive affect was associated with concurrent substance use. 
Reports of craving motives were compared to ratings of current craving, which was assessed using three items $(\alpha=.84$ across all smoking reports) adapted from the Wisconsin Smoking Withdrawal Scale (Welsch et al., 1999). The item stem and the Likert scale were identical to those for the affect items. Current craving was not assessed in the quick smoke interviews.

To evaluate reports of smoking as an opportunity to socialize, we examined how frequently subjects chose the response option "socializing" to a question about current activity. We also examined how often smokers reported being alone in response to a question about current social contacts and how frequently participants endorsed seeing a friend smoke in the past 15 minutes. These items were included in both presmoking and quick smoke interviews. We also tested whether socializing motive was associated with consumption of alcohol and marijuana.

To probe reports of smoking to take a break from work or studying, we evaluated how frequently "studying" and "working" and "reading" were endorsed as responses to the current activity item. We also examined the frequency with which "work" was endorsed in response to a question about current location administered in both kinds of smoking interviews.

The interviews did not contain obvious criteria against which to evaluate reports of smoking due to boredom/to kill time, habit/ automatic, or soon going where can't smoke.

Psychometric motives for smoking. The Wisconsin Inventory of Smoking Dependence Motives (WISDM-68; Piper et al., 2004) was administered at orientation. The WISDM-68 is a 68 -item questionnaire comprising 13 subscales tapping theoretically derived motivational processes. We were interested in assessing whether smokers' scores on WISDM-68 subscales would predict the frequency with which they endorsed conceptually related motives for smoking cigarettes in the diary record. Therefore, analyses focused on seven subscales with relatively straightforward analogs in the diary-based motive checklist. The tested subscales were Negative Reinforcement $(\alpha=.81$; tested as a predictor of endorsing smoking to cope with negative emotion in diary records), Positive Reinforcement ( $\alpha=.86$; predicting smoking to enhance positive emotions), Craving ( $\alpha=.82$; predicting smoking to reduce craving), Social-Environmental Goads ( $\alpha=.90$; predicting smoking for an opportunity to socialize), Automaticity ( $\alpha=.88$; predicting smoking due to habit/automatic processes), Cognitive Enhancement ( $\alpha=.94$; predicting smoking because of boredom or to taking a break from work or studying), and Loss of Control ( $\alpha=.84$; predicting smoking because of anticipating going where smoking was restricted).

Associations between these WISDM-68 subscales and measures of smoking intensity (FTND scores and daily smoking status) were also tested to assess whether the pattern of associations with dependence and smoking status are consistent across the psychometric and diary-based measures of motives for smoking.

\section{Statistical Analyses}

The prevalence of individual self-monitored motives was calculated for the entire sample of smokers. Odds ratios (ORs) were computed to assess (a) bivariate associations between individual motives for smoking, (b) associations between motives for smoking and tobacco dependence and daily smoking status, (c) associations between contemporaneous validators and congruent motives for smoking, and (d) associations between WISDM-68 subscales and congruent diary-based motives for smoking. ORs were calculated in separate generalized estimating equations analyses using STATA software (StataCorp, College Station, TX). Generalized estimating equations were used to account for the clustering of observations within subjects. A first-order autoregressive working correlation structure was used in the reported analyses; findings were very similar when alternative working structures were specified. Continuously scaled predictors (tobacco dependence scores, negative affect, positive affect, craving, WISDM-68 subscales) were standardized before entry into generalized-estimatingequation models so that the ORs would reflect the impact of a $1-S D$ change in the measure.

\section{Results}

\section{Descriptive Findings}

The smoking records contained 124 unique combinations of motives. A single motive was chosen on $34.7 \%$ of smoking occasions, two motives were endorsed on $38.0 \%$ of smoking events, three motives were endorsed in $17.6 \%$ of smoking events, and four or more motives were endorsed in $7.4 \%$ of the smoking records. Considered singly, craving was the most commonly reported motive (62.8\% of smoking occasions), followed by habit/automatic (42.1\%), opportunity to socialize $(23.0 \%)$, boredom/time to kill (20.0\%), soon going where can't smoke (14.9\%), enhance positive emotion (11.8\%), break from work or studying (10.3\%), and cope with negative emotion $(10.2 \%)$. At least one nondependence motive was reported for $57.9 \%$ of cigarettes. At least one dependencelike motive was reported for $81.8 \%$ of cigarettes.

Table 1 summarizes bivariate associations between pairs of motives for smoking. As would be expected, rates of coendorsement were strongly related to the base rates of endorsing the individual motives. Odds ratios formally testing the association between pairs of motives are given below the diagonal in Table 1. Significant associations generally reflect negative relations between pairs of nondependence and dependence-like motives (e.g., craving-socialize; habit/automatic-break from work/study) or incompatible states (e.g., positive emotion-boredom).

A combination of at least one nondependence motive and at least one dependence-like motive was present for $42.1 \%$ of cigarettes. In $15.8 \%$ of cigarette events, only nondependence motive(s) were reported. Only dependence-like motive(s) were reported in $39.8 \%$ of smoking occasions. ${ }^{1}$

\section{Contemporaneous Validation of Diary Motives}

Table 2 summarizes analyses probing the validity of smokers' self-monitored motives for smoking. When smokers reported smoking to cope with negative affect, they reported more negative affect and more stressors than they did when they did not endorse this motive. Smokers reported increased positive affect and more

\footnotetext{
${ }^{1}$ A formal test of the association between the broad motive categories was not performed because, owing to the aggregation rule, it was not possible to report the absence of both nondependence and dependence-like motives. Therefore, a complete fourfold contingency table could not be constructed.
} 
Table 1

Bivariate Associations Between Self-Monitored Motives for Smoking

\begin{tabular}{|c|c|c|c|c|c|c|c|c|}
\hline Motive for smoking & 1 & 2 & 3 & 4 & 5 & 6 & 7 & 8 \\
\hline 1. Reduce craving & - & 25.6 & 11.0 & 12.2 & 10.4 & 5.7 & 6.9 & 5.2 \\
\hline 2. Habit/automatic & 0.89 & - & 11.6 & 7.5 & 6.0 & 6.6 & 2.5 & 3.3 \\
\hline 3. Opportunity to socialize & $0.51^{* *}$ & 1.14 & - & 3.7 & 2.0 & 4.8 & 1.8 & 1.7 \\
\hline 4. Boredom/to kill time & 0.79 & $0.73^{*}$ & 0.73 & - & 2.3 & 1.5 & 2.3 & 1.8 \\
\hline 5. Soon going where can't smoke & 1.15 & 0.76 & $0.47^{* * *}$ & 0.68 & - & 1.6 & 1.1 & 1.6 \\
\hline 6. Enhance positive emotion & $0.64^{*}$ & 1.26 & 1.44 & $0.60^{*}$ & 0.83 & - & 0.6 & 1.1 \\
\hline 7. Break from work or studying & 0.94 & $0.48^{* *}$ & 0.74 & 0.90 & 0.60 & 0.66 & - & 1.5 \\
\hline 8. Cope with negative emotion & $0.70^{*}$ & $0.64^{*}$ & $0.60^{*}$ & 0.75 & 0.98 & 0.63 & 1.50 & - \\
\hline
\end{tabular}

Note. Values above the diagonal represent the percent of smoking occasions for which both motives were endorsed. Values below the diagonal are odds ratios.

${ }^{*} p<.05 .^{* *} p<.01$.

alcohol and marijuana use when they reported smoking to enhance positive emotion. Craving scores were elevated when desire to reduce craving was cited as a motive for smoking.

When smokers reported they were smoking because it afforded an opportunity to socialize, they were more likely to report socializing as their current activity, to be in the presence of friends who were smoking, and were less likely to report being alone than when they did not endorse socializing as a motive. Smoking to socialize was significantly associated with recent alcohol consumption but not to past-hour marijuana use. When taking a break from work or studying was endorsed, smokers were more likely to report studying, working, and reading as current activities and more likely to report work as their current location than when this motive was not endorsed.

\section{Associations with Tobacco Dependence}

Table 3 summarizes associations between the self-monitored motives for smoking and FTND scores. At higher levels of dependence, smokers were more likely to report smoking to reduce craving and because of habit/automatic processes. More dependent smokers were less likely to report smoking because it afforded an opportunity to socialize and smoking to cope with negative emotion. The prevalence of citing any nondependence motive did not vary with dependence score, but the prevalence of dependence-like motives was significantly related to FTND scores. More dependent smokers were less likely to exclusively attribute individual cigarettes to nondependence motives but were not significantly more likely to exclusively cite dependence-like motives. Table 4 summarizes corresponding analyses using daily smoking as the predictor. Results were similar to analyses involving the FTND, with the exception that smoking to socialize was unrelated to daily smoking.

\section{Relations Between WISDM-68 Subscales and Diary Motives}

In four instances, no relation was found between psychometrically assessed smoking motives and congruent diary-based motives. Scores on the Negative Reinforcement subscale were not related to the frequency of endorsing smoking to cope with negative emotion, $\mathrm{OR}=1.02,95 \%$ confidence interval $(\mathrm{CI})=$ $0.81-1.29, p=.87$. Positive Reinforcement subscale scores were not related to smoking to enhance positive emotion $(\mathrm{OR}=$ $1.03,95 \%$ CI $=0.80-1.31, p=.83$ ). Cognitive enhancement scores were unrelated to either smoking to alleviate boredom $(\mathrm{OR}=1.10,95 \% \mathrm{CI}=0.91-1.32, p=.32)$ or smoking to take

Table 2

Associations Between Self-Monitored Motives for Smoking and Contemporaneous, Conceptually Related States and Circumstances

\begin{tabular}{|c|c|c|c|c|c|}
\hline Motive for smoking & Validation measure & Motive present & Motive absent & OR & $95 \% \mathrm{CI}$ \\
\hline \multirow[t]{2}{*}{ Cope with negative emotion } & Negative affect, $M(S D)$ & $6.40(2.66)$ & $3.58(1.44)$ & 2.78 & $2.32,3.35$ \\
\hline & Stressor onset & 43.4 & 9.3 & 7.08 & $4.53,11.07$ \\
\hline \multirow{3}{*}{ Enhance positive emotion } & Positive affect, $M(S D)$ & $6.98(3.31)$ & $5.05(2.51)$ & 1.91 & $1.58,2.31$ \\
\hline & Alcohol & 16.5 & 5.2 & 3.12 & $1.69,5.78$ \\
\hline & Marijuana & 11.0 & 1.5 & 6.53 & $2.92,14.59$ \\
\hline Reduce craving & Craving, $M(S D)$ & $7.68(3.05)$ & $5.71(3.04)$ & 1.80 & $1.52,2.14$ \\
\hline \multirow[t]{5}{*}{ Opportunity to socialize } & Socializing & 66.9 & 25.1 & 3.99 & $2.99,5.31$ \\
\hline & Alone & 10.5 & 34.8 & 0.32 & $0.22,0.45$ \\
\hline & Friends smoking & 90.4 & 59.7 & 5.16 & $2.55,10.43$ \\
\hline & Alcohol & 14.2 & 4.4 & 3.37 & $2.04,5.56$ \\
\hline & Marijuana & 2.8 & 2.5 & 1.03 & $0.44,2.42$ \\
\hline \multirow[t]{4}{*}{ Break from work or studying } & Studying & 62.3 & 7.8 & 16.48 & $10.35,26.23$ \\
\hline & Working & 17.5 & 6.7 & 3.03 & $1.81,5.08$ \\
\hline & Reading & 5.3 & 1.0 & 4.68 & $1.75,12.54$ \\
\hline & At work & 10.5 & 0.8 & 13.95 & $5.47,35.55$ \\
\hline
\end{tabular}

Note. Except as indicated, data are percentages of occasions for which the criterion measure was endorsed in the presence or absence of the motive for smoking. $\mathrm{OR}=$ odds ratio (predicting motive from validation measure); $\mathrm{CI}=$ confidence interval. 
Table 3

Associations Between Self-Monitored Motives for Smoking and Baseline Dependence Scores

\begin{tabular}{lccc}
\hline \multicolumn{1}{c}{ Motive for smoking } & $\begin{array}{c}\text { FTND }>0 \\
(n=20)\end{array}$ & $\begin{array}{c}\text { FTND }=0 \\
(n=30)\end{array}$ & $\begin{array}{c}\text { FTND } \\
\text { OR (95\% CI) }\end{array}$ \\
\hline Reduce craving & 70.7 & 54.0 & $1.53(1.29,1.81)$ \\
Habit/automatic & 45.3 & 38.4 & $1.20(1.04,1.39)$ \\
Opportunity to socialize & 14.5 & 32.5 & $0.56(0.45,0.69)$ \\
Boredom/to kill time & 20.7 & 19.3 & $1.02(0.87,1.19)$ \\
Soon going where can't smoke & 12.8 & 17.3 & $1.05(0.88,1.24)$ \\
Enhance positive emotion $_{\text {Break from work or studying }}$ & 13.0 & 10.4 & $1.12(0.92,1.36)$ \\
Cope with negative emotion $_{\text {Any nondependence motive }}^{\mathrm{a}}$ & 12.5 & 7.8 & $1.15(0.94,1.41)$ \\
Any dependence-like motive $^{\mathrm{b}}$ & 7.5 & 13.2 & $0.74(0.60,0.92)$ \\
${\text { Only nondependence motive }(\mathrm{s})^{\mathrm{c}}}^{\mathrm{c}}$ & 55.2 & 60.9 & $0.88(0.76,1.01)$ \\
Only dependence-like motive(s) $^{\mathrm{d}}$ & 87.7 & 75.3 & $1.91(1.51,2.40)$ \\
\hline
\end{tabular}

Note. Data are the percentages of smoking occasions for which the motive was endorsed in each subgroup. FTND $=$ Fagerstrom Test for Nicotine Dependence; OR = odds ratio (based on standardized FTND scores) $\mathrm{CI}=$ confidence interval.

${ }^{a}$ Report of at least one of the following: opportunity to socialize, boredom/to kill time, enhance positive emotion, break from work or studying, or cope with negative emotion.

${ }^{\mathrm{b}}$ Report of at least one of the following: reduce craving, habit/automatic, or soon going where can't smoke.

${ }^{\mathrm{c}}$ Report of at least one nondependence motive and no dependence-like motive reported.

${ }^{\mathrm{d}}$ Report of at least one dependence-like motive and no nondependence motive reported.

a break from work or studying $(\mathrm{OR}=1.07,95 \% \mathrm{CI}=0.83-$ $1.38, p=.58)$. In three analyses, evidence for congruence was found. Automaticity subscale scores predicted the frequency with which students endorsed smoking for habit/automatic reasons $(\mathrm{OR}=1.36,95 \% \mathrm{CI}=1.15-1.62, p<.01)$. The Craving subscale was associated with endorsing smoking to reduce craving $(\mathrm{OR}=1.76,95 \% \mathrm{CI}=1.44-2.15, p<.01)$. Attributing smoking to soon going where smoking was not permitted was predicted by the Loss of Control subscale (OR $=1.30,95 \%$ $\mathrm{CI}=1.07-1.58, p<.01)$. Contrary to expectation, scores on the Social-Environmental Goads subscale were negatively re- lated to endorsing smoking for an opportunity to socialize in diary records $(\mathrm{OR}=0.72,95 \% \mathrm{CI}=0.59-0.88, p<.01)$.

\section{WISDM-68 Subscales, Tobacco Dependence, and Daily Smoking}

Correlations between the FTND and WISDM-68 subscales were all positive and small to moderate in magnitude ( $r \mathrm{~s}=.19-.37)$. The FTND was significantly correlated with two subscales; Social/ Environmental Goads $(r=.36, p=.01)$ and Loss of Control $(r=$ $.37, p<.01)$. As Table 5 shows, daily smokers reported signifi-

Table 4

Associations Between Self-Monitored Motives for Smoking and Daily Smoking Status

\begin{tabular}{lccc}
\hline \multicolumn{1}{c}{ Motive for smoking } & $\begin{array}{c}\text { Daily smokers } \\
(n=33)\end{array}$ & $\begin{array}{c}\text { Nondaily smokers } \\
(n=17)\end{array}$ & OR (95\% CI) \\
\hline Reduce craving & 67.7 & 33.1 & $4.15(2.44,7.06)$ \\
Habit/automatic & 44.5 & 27.6 & $2.23(1.31,3.81)$ \\
Opportunity to socialize & 23.6 & 19.6 & $1.23(0.66,2.27)$ \\
Boredom/to kill time & 20.2 & 19.0 & $1.00(0.58,1.71)$ \\
Soon going where can't smoke & 15.9 & 9.2 & $1.78(0.90,3.53)$ \\
Enhance positive emotion & 12.0 & 10.4 & $1.10(0.55,2.22)$ \\
Break from work or studying & 10.1 & 11.0 & $0.89(0.44,1.82)$ \\
Cope with negative emotion & 8.8 & 18.4 & $0.40(0.24,0.69)$ \\
Any nondependence motive & 57.9 & 57.7 & $0.89(0.54,1.46)$ \\
Any dependence-like motive & 86.4 & 54.6 & $5.55(3.42,9.02)$ \\
${\text { Only nondependence motive }(\mathrm{s})^{\mathrm{c}}}^{\mathrm{b}}$ & 11.7 & 40.5 & $0.18(0.11,0.29)$ \\
${\text { Only dependence-like motive }(\mathrm{s})^{\mathrm{d}}}^{\mathrm{d}}$ & 40.2 & 37.4 & $1.13(0.69,1.86)$ \\
\hline
\end{tabular}

Note. Data are percentages of smoking occasions for which the motive was endorsed in each subgroup. OR $=$ odds ratio; $\mathrm{CI}=$ confidence interval.

${ }^{a}$ Report of at least one of the following: opportunity to socialize, boredom/to kill time, enhance positive emotion, break from work or studying, or cope with negative emotion.

${ }^{\mathrm{b}}$ Report of at least one of the following: reduce craving, habit/automatic, or soon going where can't smoke.

${ }^{\mathrm{c}}$ Report of at least one nondependence motive and no dependence-like motive reported.

${ }^{\mathrm{d}}$ Report of at least one dependence-like motive and no nondependence motive reported. 
Table 5

Wisconsin Inventory of Smoking Dependence (WISDM-68) Subscale Scores by Daily Smoking Status

\begin{tabular}{|c|c|c|c|c|c|}
\hline \multirow[b]{2}{*}{ WISDM-68 subscale } & \multicolumn{2}{|c|}{$\begin{array}{l}\text { Daily smokers } \\
\qquad(n=33)\end{array}$} & \multicolumn{2}{|c|}{$\begin{array}{l}\text { Nondaily smokers } \\
\qquad(n=17)\end{array}$} & \multirow[b]{2}{*}{$p$} \\
\hline & $M$ & $S D$ & $M$ & $S D$ & \\
\hline Social/environmental goads & 5.02 & 1.36 & 3.21 & 1.56 & $<.001$ \\
\hline Negative reinforcement & 4.30 & 1.10 & 3.48 & 1.40 & $<.05$ \\
\hline Positive reinforcement & 3.99 & 1.22 & 2.93 & 1.30 & $<.01$ \\
\hline Craving & 3.91 & 1.44 & 2.43 & 1.16 & $<.01$ \\
\hline Cognitive enhancement & 3.49 & 1.61 & 2.02 & 1.49 & $<.01$ \\
\hline Automaticity & 3.17 & 1.47 & 2.05 & 1.18 & $<.01$ \\
\hline Loss of control & 2.88 & 1.27 & 1.74 & 1.49 & $<.01$ \\
\hline
\end{tabular}

Note. WISDM-68 subscale scores have been transformed to the original response scale (i.e., subscale sums divided by the number of subscale items) to facilitate comparison of relative motive strengths.

cantly higher scores than nondaily smokers on all of the tested WISDM-68 subscales. Relative to findings based on diary records, analyses of the WISDM-68 subscales suggested a distinctive ranking of motive strengths (Tables 3-5) and a different pattern of associations with the FTND and daily smoking status.

\section{Discussion}

A desire to reduce craving was the most commonly cited motive for smoking among college student smokers. Craving was the only motive to be endorsed on more than half of the smoking occasions. Habit/automatic was the second most frequently endorsed motive, occurring in $42 \%$ of smoking records. Other motives (socializing, boredom, taking a break, affect modulation, anticipation of smoking restrictions) were less common, occurring in fewer than one quarter of smoking reports. As expected, college smokers attributed a majority of their cigarettes $(57.9 \%)$ to fairly specific, nondependence motives relevant at any stage of the smoking career. Surprisingly, dependence-like processes (craving, smoking in anticipation of restrictions, automaticity) were cited more frequently $(81.8 \%$ of smoking entries), and only $15.8 \%$ of smoking records were attributed exclusively to nondependence motives.

Interestingly, a desire to cope with negative emotion was the least frequently endorsed motive and was cited in only $10.2 \%$ of smoking records. Smokers strongly believe they smoke to cope with negative affect (e.g., Brandon \& Baker, 1991; Shiffman, 1993), and we observed this phenomenon (Table 5). Our findings complement other recent diary studies (cf. Shapiro, Jamner, Davydov \& James, 2002; Shiffman et al., 2002; Shiffman, Paty, Gwaltney \& Dang, 2004) in suggesting that craving, not negative affect, is the most common antecedent of smoking. However, smokers did endorse smoking to relieve negative affect; and, when they did so, they tended to report elevated negative affect and recent stressors. This suggests a potential advantage of integrating assessment of self-monitored motives within a larger EMA design; event-based appraisals might flag moments in which rare motives are operative, even if conceptually related stimuli do not emerge as robust correlates of smoking across the monitoring period. ${ }^{2}$
As expected, motives for smoking differed by dependence level. At higher levels of dependence, students more frequently endorsed smoking to reduce craving and for habit/automatic reasons and less frequently endorsed smoking to cope with negative emotion and for an opportunity to socialize. Similar findings were obtained for daily smoking. Interestingly, analyses of conceptually aggregated motives suggested that the rate of nondependence motives did not differ by dependence level. However, the tendency to report any dependence-like motive was strongly related to FTND score and daily smoking. Daily and dependent smokers were less likely to exclusively cite nondependence motives for particular cigarettes. Taken together, these findings are consistent with the notion that smoking becomes less stimulus-bound and more functionally autonomous as tobacco dependence progresses (Leventhal \& Cleary, 1980; Shiffman \& Paty, 2006). Although dependence-like motives were especially prominent in the diary records of heavier smokers, the data caution against overlooking these motives among light smokers. Craving and habit were the most commonly reported motives for smoking among smokers with FTND scores of 0 and among nondaily smokers (Tables 3 and 4).

Craving appears to accompany smoking at various stages of use (Riedel, Robinson, Klesges, \& McLain-Allen, 2003; Rojas, Killen, Haydel, \& Robinson, 1998; Shiffman \& Paty, 2006). Craving may be an early-arising sign of dependence produced by sensitization of incentive systems in response to initial nicotine exposures (e.g., Robinson \& Berridge, 1993). Self-reports of craving may be especially likely when a self-administration sequence is interrupted and controlled processing is recruited (Tiffany, 1990).

\footnotetext{
${ }^{2}$ Indeed, comparisons of data from signaled prompts and smokingrelated recordings in this sample showed a modest negative association between negative affect and smoking $(\mathrm{OR}=0.91,95 \% \mathrm{CI}=0.84-0.98)$. Recent stressors were more frequently reported in smoking records, but not significantly so $(\mathrm{OR}=1.20,95 \% \mathrm{CI}=0.95-1.51)$.
} 
Self-monitoring tasks create these conditions, and could contribute to the high rate of craving motive endorsement. ${ }^{3}$

Habit/automatic motives theoretically reflect the acquisition of a highly practiced self-administration routine activated by contextual or interoceptive stimuli without effortful cognitive processing (e.g., Baker, Piper, McCarthy, Majeskie, \& Fiore, 2004; Tiffany, 1990). As habit strength increases, actions become less dependent on conscious intentions and more resistant to change (Neal, Wood, \& Quinn, 2006). One might expect habit/automatic processes to be endorsed only when the smoker is not aware of other motives. However, at least one other motive was reported in the majority of occasions for which the habit/automatic option was selected (Table 1). This may be a by-product of self-monitoring, which interrupts the self-administration sequence and encourages scrutiny of present motivation. Habit/automatic reports may indicate some recognition that co-present motives were insufficient explanations for smoking and that important, nonintentional processes were in play.

We expected smoking attributed to anticipation of going somewhere smoking was not permitted to be a good indicator of dependence, indexing a desire to "load up" on nicotine to avert future withdrawal symptoms. This motive was related to the WISDM-68 Loss of Control subscale but not significantly associated with dependence or daily smoking. This may suggest withdrawal symptoms are late-emerging components of dependence not yet evident in most college students. Alternatively, college life may not frequently press for this behavior because students may only encounter brief periods of smoking restriction (e.g., hour-long lectures), separated by free time in which they have considerable discretion over activities and locations.

A secondary aim of this study was to evaluate the construct and discriminant validity of self-monitored motives for smoking. Reassuringly, self-monitored motives broadly accorded with reports of conceptually related states and circumstances measured in other portions of the diary interview. Notably, these motive-validator relations were imperfect. For example, on $25 \%$ of occasions when opportunity to socialize was not endorsed, socializing was reported as a current activity (Table 2). This undoubtedly reflects some measurement error. Another interpretation is that stimulus conditions may be imprecise proxies for the functions of smoking at the event level. Smokers' immediately reported motives may be useful for distinguishing between influential and spuriously present stimulus conditions within a given momentary report.

We compared findings based upon WISDM-68 subscales and diary-based motives. Inferences about the relative importance of particular motives for smoking would clearly differ by assessment method. For example, the pattern of mean scores on the WISDM-68 subscales (e.g., Table 5) would suggest that negative reinforcement is a prime driver of smoking in college students, whereas craving is of modest importance and automatic processes not very influential.

Conclusions about the association of particular motives with dependence level also differed across methods. All WISDM-68 subscales were positively correlated with the FTND (only two correlations were significant). Scores on all WISDM-68 subscales were higher among daily smokers than among nondaily smokers. These findings are consistent with the suggestion that smoking motives questionnaires tap a higher order factor indicating dependence or drive to smoke (Piper et al., 2004; Shiffman, 1993).
Individual differences on WISDM-68 subscales only partially forecasted the frequency of conceptually related motives for smoking in diary records, suggesting the subscales differed in their ecological validity. Notably, only scales tapping dependence-like motives (Automaticity, Craving, and Loss of Control) predicted the frequency of congruent motives in the diary records. Interestingly, Social/Environmental Goads scores were negatively related to self-monitoring reports of smoking to socialize. This subscale measures the density of smokers in the respondent's social network and was related to daily smoking and dependence, consistent with prior research (Ridner, 2005; Stockdale, Dawson-Owens, \& Sagrestano, 2005; Wetter et al., 2004). Opportunities to socialize explained a minority of day-to-day smoking events, and socializing motives were less common at higher levels of tobacco dependence. In another ecological study of college smoking, Krukowski et al. (2005) found heavier smokers spent more time with other smokers, but the presence of other smokers only predicted smoking in light smokers. As smokers progress toward dependence, they may surround themselves with smokers (niche-seeking) but no longer require the presence or approval of other smokers to light up.

Retrospective motives questionnaires, such as the WISDM-68, may tap the subjective importance of different smoking effects, not their likelihood or frequency. Different questionnaire response formats might reveal closer correspondence with momentary reports. Similarly, self-monitored motives for smoking are dependent upon the base rates of important daily experiences. Some motives (e.g., habit/automatic) can be endorsed anytime a cigarette is smoked. Others (e.g., socializing, cope with negative emotion) require the presence of the appropriate setting event. Some discrepancies across modes of assessment need not be logically inconsistent. For example, negative reinforcement may be an especially valued but rarely needed function of smoking. People typically only have access to their own appraisals of their motives and past experiences to guide future decision making (e.g., Wirtz, Kruger, Scollon, \& Diener, 2003). Thus, smokers' general beliefs about their reasons for smoking may have important real-world implications even if they do not accord with diary records.

Discrepancies across assessment modes may suggest the potential for novel intervention strategies among college students. Diary monitoring might be used to demonstrate to young smokers that their immediate decisions about smoking more closely correspond to the profiles expected of addicts than to their own beliefs about their smoking. This approach may be tractable; two studies have shown college students' appraisals of their typical reasons for smoking change after a bout of self-monitoring (Klitzke et al., 1990; Leventhal \& Avis, 1976).

This study had several limitations that should be considered. We were able to examine self-monitored motives from a large number

\footnotetext{
${ }^{3}$ The craving motive was always the first listed response option in the diary interview, which could contribute to the high frequency of craving reports. It is unlikely that the findings are attributable exclusively to the position of response options because craving motives were associated with elevated current craving, dependence, and daily smoking. The modal number of motives endorsed was 2, suggesting respondents frequently considered multiple response options. Rates of other motives did not reflect checklist position (e.g., habit/automatic, the second most frequent, listed fifth, and cope with negative emotion, the least frequent, listed third).
} 
of smoking events, but these were logged by a small sample of student smokers. The sample was predominately white and drawn from a single institution. Future research is needed to determine the generalizability of the findings. Analyses involving tobacco dependence and smoking history relied on between-subjects, cross-sectional comparisons. The checklist of potential motives was clearly not exhaustive; we did not provide explicit instruction about the intended meaning of checklist options; and the checklist allowed endorsement of multiple motives for a cigarette. Different findings might be obtained with other motive questions, more explicit instructions, or an instruction that smokers rate a single, most important motive (cf. Joffe et al., 1981; Tate \& Stanton, 1990). Smokers are likely to have incomplete conscious insight into their own motives (Curtin, McCarthy, Piper, \& Baker, 2006; Shiffman \& Prange, 1988; Waters \& Sayette, 2006). Thus, immediately assessed attributions for smoking may be best used as one element of a broader, multichannel assessment strategy.

Self-reported smoking rates correlated significantly with the number of diary-recorded smoking events, but participants reported only about one third of the cigarettes we would have projected. If compliance with smoking recording was selective, this would adversely affect the generalizability of our findings regarding the relative frequencies and correlates of self-monitored motives for smoking. Discrepancies between expected and diaryrecorded smoking rates could be regarded as conservative. These estimates treat self-reported cigarettes per day as a gold standard, but reports of typical smoking may be error-prone among college students with light and variable smoking habits (Krukowski et al., 2005). Behavioral reactivity is a concern in any self-monitoring study of smoking and may be more pronounced in samples of college students with low dependence levels. Thus, one interpretation of the difference between expected and recorded cigarettes might be that smoking among college students is amenable to self-monitoring or scheduled reduction interventions (Cinciripini et al., 1995; McFall \& Hammen, 1971). Ultimately, we lack the objective or informant data needed to determine the relative contributions of measurement error, reactivity, and noncompliance to the rates of smoking-related recording in this study. ${ }^{4}$ Diary recording requirements might be important moderating factors in compliance with recording of ongoing smoking behavior (cf. Shapiro et al., 2002; Shiffman et al., 2002), and this topic deserves attention in future research.

In summary, the present study suggests that craving and an automatized self-administration ritual are the most common immediately reported motives for smoking among college students. These motives are more frequently endorsed by regular, dependent student smokers but were surprisingly common in lighter, nondependent smokers as well. Methodologically, our findings suggest self-monitored motives have reasonable validity and may contribute unique information to a comprehensive assessment of smoking motivation.

\footnotetext{
${ }^{4}$ We gave participants paper logs and asked them to record and explain any times they did not carry the PDA on their person during the monitoring period. The vast majority of completed log entries provided explanations for missed random prompts (e.g., forgetting the PDA at a friend's house, not responding while driving). Only one participant reported incidents reflecting situational bias in smoking recording
}

(twice deliberately leaving the PDA at home to be unencumbered while attending parties at which she smoked). Though reports of situational bias were rare, it is prudent to assume this occurred more commonly than it was reported to us.

\section{References}

Baker, T. B., Piper, M. E., McCarthy, D. E., Majeskie, M. R., \& Fiore, M. C. (2004). Addiction motivation reformulated: An affective processing model of negative reinforcement. Psychological Review, 111, 35-51.

Brandon, T. H., \& Baker, T. B. (1991). The Smoking Consequences Questionnaire: The subjective expected utility of smoking in college students. Psychological Assessment, 3, 484-491.

Cinciripini, P. M., Lapitsky, L., Seay, S., Wallfisch, A., Kitchens, K., \& Van Vunakis, H. (1995). The effects of smoking schedules on cessation outcome: Can we improve on common methods of gradual and abrupt nicotine withdrawal? Journal of Consulting and Clinical Psychology, 63, 388-399.

Colby, S. M., Tiffany, S. T., Shiffman, S., \& Niaura, R. S. (2000). Measuring nicotine dependence among youth: A review of available approaches and instruments. Drug and Alcohol Dependence, 59 (Suppl. 1), $\mathrm{S} 23-\mathrm{S} 39$.

Colder, C. R., Lloyd-Richardson, E. E., Flaherty, B. R., Hedeker, D., Segawa, E., \& Flay, B. R. (2006). The natural history of college smoking: Trajectories of daily smoking during the freshman year. $A d-$ dictive Behaviors, 31, 2212-2222.

Csikszentmihalyi, M., \& Larson, R. (1987). Validity and reliability of the Experience-Sampling Method. Journal of Nervous \& Mental Disease, $175,526-537$.

Curtin, J. J., McCarthy, D. E., Piper, M. E., \& Baker, T. B. (2006). Implicit and explicit drug motivational processes: A model of boundary conditions. In R. W. Wiers \& A. W. Stacy (Eds.). Handbook of implicit cognition and addiction (pp. 233-250). Thousand Oaks, CA: Sage.

DeBernardo, R. L., \& Aldinger, C. E. (1999). An email assessment of undergraduates' attitudes toward smoking. Journal of American College Health, 48, 61-67.

Green, A. S., Rafaeli, E., Bolger, N., Shrout, P. E., \& Reis, H. T. (2006). Paper or plastic? Data equivalence in paper and electronic diaries. Psychological Methods, 11, 87-105.

Heatherton, T. F., Kozlowski, L. T., Frecker, R. C., \& Fagerstrom, K. O. (1991). The Fagerstrom Test for Nicotine Dependence: A revision of the Fagerstrom Tolerance Questionnaire. British Journal of Addiction, 86, $1119-1127$

Horn, D., \& Waingrow, S. (1966). Some dimensions of a model for smoking behavior change. American Journal of Public Health, 56 , 21-26.

Joffe, R., Lowe, M. R., \& Fisher, E. B. (1981). A validity test of the Reasons for Smoking Scale. Addictive Behaviors, 6, 41-45.

Johnston, L. D., O’Malley, P. M., Bachman, J. G., \& Schulenberg, J. E. (2005). Monitoring the Future national survey results on drug use, 1975-2004. Volume II: College students and adults ages 19-45 (NIH Publication No. 05-5728). Bethesda, MD: National Institute on Drug Abuse.

Kenford, S. L., Wetter, D. W., Welsch, S. K., Smith, S. S., Fiore, M. C., \& Baker, T. B. (2005). Progression of college-age cigarette samplers: What influences outcome. Addictive Behaviors, 30, 285-294.

Klitzke, M., Irwin, R., Lombardo, T. W., \& Christoff, K. A. (1990). Self-monitored smoking motives. Journal of Substance Abuse, 2, 121127.

Krukowski, R. A., Solomon, L. J., \& Naud, S. (2005). Triggers of heavier and lighter cigarette smoking in college students. Journal of Behavioral Medicine, 28, 335-345.

Leventhal, H., \& Avis, N. (1976). Pleasure, addiction, and habit: Factors in verbal report or factors in smoking behavior? Journal of Abnormal Psychology, 85, 478-488. 
Leventhal, H., \& Cleary, P. D. (1980). The smoking problem: A review of the research and theory in behavioral risk modification. Psychological Bulletin, 88, 370-405.

Mayhew, K. P., Flay, B. R., \& Mott, J. A. (2000). Stages in the development of adolescent smoking. Drug and Alcohol Dependence, 59(Suppl. 1), S61-S81.

McFall, R. M., \& Hammen, C. L. (1971). Motivation, structure, and self-monitoring: Role of nonspecific factors in smoking reduction. Journal of Consulting and Clinical Psychology, 37, 80-86.

Moran, S., Wechsler, H., \& Rigotti, N. A. (2004). Social smoking among U.S. college students. Pediatrics, 114, 1028-1034.

Neal, D. T., Wood, W., \& Quinn, J. M. (2006). Habits-a repeat performance. Current Directions in Psychological Science, 15, 198-202.

Nichter, M., Nichter, M., Lloyd-Richardson, E. E., Flaherty, B., Carkoglu, A., \& Taylor, N. (2006). Gendered dimensions of smoking among college students. Journal of Adolescent Research, 21, 215-243.

Piper, M. E., Piasecki, T. M., Federman, E. B., Bolt, D. M., Smith, S. S., Fiore, M. C., \& Baker, T. B. (2004). A multiple motives approach to tobacco dependence: The Wisconsin Inventory of Smoking Dependence Motives (WISDM-68). Journal of Consulting and Clinical Psychology, 72, 139-154.

Ridner, S. L. (2005). Predicting smoking status in a college-age population. Public Health Nursing, 22, 494-505.

Riedel, B. W., Robinson, L. A., Klesges, R. C., \& McLain-Allen, B. (2003). Ethnic differences in smoking withdrawal effects among adolescents. Addictive Behaviors, 28, 129-140.

Rigotti, N. A., Lee, J. E., \& Wechsler, H. (2000). US college students' use of tobacco products: Results of a national survey. Journal of the American Medical Association, 284, 699-705.

Robinson, T. E., \& Berridge, K. C. (1993). The neural basis of drug craving: An incentive sensitization theory of addiction. Brain Research Reviews, 18, 247-291.

Rojas, N. L., Killen, J. D., Haydel, K. F., \& Robinson, T. N. (1998). Nicotine dependence among adolescent smokers. Archives of Pediatrics \& Adolescent Medicine, 152, 151-156.

Schwartz, J. E., Neale, J., Marco, C., Shiffman, S. S., \& Stone, A. A. (1999). Does trait coping exist? A momentary assessment approach to the evaluation of traits. Journal of Personality and Social Psychology, $77,360-369$

Shapiro, D., Jamner, L. D., Davydov, D. M., \& James, P. (2002). Situations and moods associated with smoking in everyday life. Psychology of Addictive Behaviors, 16, 342-345.

Shiffman, S. (1993). Assessing smoking patterns and motives. Journal of Consulting and Clinical Psychology, 61, 732-742.

Shiffman, S., Gwaltney, C. J., Balabanis, M. H., Liu, K. S., Paty, J. A., Kassel, J. D., et al. (2002). Immediate antecedents of cigarette smoking: An analysis from ecological momentary assessment. Journal of Abnormal Psychology, 111, 531-545.

Shiffman, S., Hufford, M., Hickcox, M., Paty, J. A., Gnys, M., \& Kassel, J. D. (1997). Remember that? A comparison of real-time versus retro- spective recall of smoking lapses. Journal of Consulting and Clinical Psychology, 65, 292-300.

Shiffman, S., \& Paty, J. (2006). Smoking patterns and dependence: Contrasting chippers and heavy smokers. Journal of Abnormal Psychology, $115,509-523$.

Shiffman, S., Paty, J. A., Gwaltney, C. J., \& Dang, Q. (2004). Immediate antecedents of cigarette smoking: An analysis of unrestricted smoking patterns. Journal of Abnormal Psychology, 113, 166-171.

Shiffman, S., \& Prange, M. (1988). Self-reported and self-monitored smoking patterns. Addictive Behaviors, 13, 201-204.

Stockdale, M. S., Dawson-Owens, H. L., \& Sagrestano, L. M. (2005) Social, attitudinal, and demographic correlates of adolescent vs. collegeage tobacco use initiation. American Journal of Health Behavior, 29. 311-323.

Stone, A. A., \& Shiffman, S. (1994). Ecological momentary assessment (EMA) in behavioral medicine. Annals of Behavioral Medicine, 16, 199-202.

Stone, A. A., Shiffman, S., Schwartz, J. E., Broderick, J. E., \& Hufford, M. R. (2002). Patient non-compliance with paper diaries. British Medical Journal, 324, 1193-1194.

Tate, J. C., Schmitz, J. M., \& Stanton, A. L. (1991). A critical review of the Reasons for Smoking Scale. Journal of Substance Abuse, 3, 441-455.

Tate, J. C., \& Stanton, A. L. (1990). Assessment of the validity of the Reasons for Smoking Scale. Addictive Behaviors, 15, 129-135.

Tiffany, S. T. (1990). A cognitive model of drug urges and drug-use behavior: Role of automatic and nonautomatic processes. Psychological Review, 97, 147-168.

Waters, A. J., \& Sayette, M. A. (2006). Implicit cognition and tobacco addiction. In R. W. Wiers \& A. W. Stacy (Eds.). Handbook of implicit cognition and addiction (pp. 309-338). Thousand Oaks, CA: Sage.

Watson, D., Clark, L. A., \& Tellegen, A. (1988). Development and validation of brief measures of positive and negative affect: The PANAS scales. Journal of Personality and Social Psychology, 54, 1063-1070.

Wechsler, H., Rigotti, N. A., Gledhill-Hoyt, J., \& Lee, H. (1998). Increased levels of cigarette use among college students: A cause for national concern. Journal of the American Medical Association, 280, 1673-1678.

Welsch, S. K., Smith, S. S., Wetter, D. W., Jorenby, D. E., Fiore, M. C., \& Baker, T. B. (1999). Development and validation of the Wisconsin Smoking Withdrawal Scale. Experimental and Clinical Psychopharmacology, 7, 354-361.

Wetter, D. W., Kenford, S. L., Welsch, S. K., Smith, S. S., Fouladi, R. T., Fiore, M. C., \& Baker, T. B. (2004). Prevalence and predictors of transitions in smoking behavior among college students. Health Psychology, 23, 168-177.

Wirtz, D., Kruger, J., Scollon, C. N., \& Diener, E. (2003). What to do on spring break? The role of predicted, on-line, and remembered experience in future choice. Psychological Science, 14, 520-524.

Received August 7, 2006 Revision received November 9, 2006 Accepted November 17, 2006 